\title{
Lactic acid bacteria and cancer: mechanistic perspective
}

\author{
J. Rafter* \\ Department of Medical Nutrition, Karolinska Institute, NOVUM, S-141 86 Huddinge, Sweden
}

\begin{abstract}
Colorectal cancer is one of the most important causes of cancer morbidity and mortality in Western countries. While a myriad of healthful effects have been attributed to the probiotic lactic acid bacteria (LAB), perhaps the most controversial remains that of anticancer activity. It should be pointed out that there is no direct experimental evidence for cancer suppression in man as a result of consumption of lactic cultures in fermented or unfermented dairy products. However, there is a wealth of indirect evidence, based largely on laboratory studies, in the literature. The precise mechanisms by which LAB may inhibit colon cancer are presently unknown. However, such mechanisms might include: alteration of the metabolic activities of intestinal microflora; alteration of physico-chemical conditions in the colon; binding and degrading potential carcinogens; quantitative and/or qualitative alterations in the intestinal microflora incriminated in producing putative carcinogen(s) and promoters (e.g. bile acidmetabolising bacteria); production of antitumourigenic or antimutagenic compounds; enhancing the host's immune response; and effects on physiology of the host. These potential mechanisms are addressed in the present paper.
\end{abstract}

Lactic acid bacteria: Intestinal microflora: Chemoprevention: Colon cancer

\section{Introduction}

An example of a functional food, which has been the focus of intense research activity in recent years, is probiotics 'live microbial feed supplements which beneficially affect the host animal by improving its intestinal microbial balance' (Salminen et al. 1998). Probiotics usually refer to highly selected lactic acid bacteria (LAB), e.g. Lactobacillus spp., Bifidobacterium spp. and Streptococcus spp., with defined gut survival properties and associated biological activities and which can be ingested in fermented milk products or as a supplement. The list of healthful effects attributed to probiotic bacteria is extensive (Salminen et al. 1998) and includes: alleviation of lactose intolerance symptoms; serum cholesterol reduction; anticancer effects; alleviation of constipation and relief of vaginitis, to name but a few. The vast majority of studies on the anticancer effects deal with colorectal cancer (CRC), although there are some studies on breast and bladder cancer. CRC is the second most common cause of mortality from malignant disease in Europe with 190000 new cases per year. Prognosis for advanced CRC is poor (Sant et al. 1995), and hence prevention is required to control the incidence of the disease. Epidemiological studies show that diet plays a role in the aetiology of most large bowel cancers, implying that it is a potentially preventable disease. Many studies confirm the involvement of the endogenous microflora in the onset of colon cancer. This makes it reasonable to think that changing the intestinal microflora could influence tumour development. Thus, considerable attention has focused on dietary supplements that can influence the gut microflora as a strategy for CRC prevention. In particular, evidence has been accumulating from animal studies for a protective role for probiotics, prebiotics ('non-digestible food ingredients that beneficially affect the host by selectively stimulating the growth and/or activity of one or a limited number of bacteria in the colon, that have the potential to improve host health'; Salminen et al. 1998) and synbiotics (combinations of pro- and prebiotics). It should be pointed out that there is no direct experimental evidence for cancer suppression in man as a result of consumption of lactic cultures in fermented or unfermented dairy products. However, there is a wealth of indirect evidence, based largely on laboratory studies, in the literature.

\section{Epidemiological studies}

As yet, there are few epidemiological studies addressing the association between fermented dairy products and colorectal cancer. Consumption of large quantities of dairy products such as yoghurt and fermented milk containing

\footnotetext{
Abbreviations: ACF, aberrant crypt foci; CRC, colorectal cancer; LAB, lactic acid bacteria; LcS, Lactobacillus casei Shirota; Trp-P-1, 3-amino-1,4dimethyl-5H-pyrido[4,3-b]indole; Trp-P-2, 3-amino-1-methyl-5H-pyrido[4,3- $b]$ indole.

* Corresponding author: Dr J. Rafter, fax +46 8 7116659, email joseph.rafter@mednut.ki.se
} 
Lactobacillus or Bifidobacterium spp. may be related to a lower incidence of colon cancer (Shahani \& Ayebo, 1980). An epidemiological study performed in Finland demonstrated that, despite a high fat intake, colon cancer incidence is lower than in other countries because of the high consumption of milk, yoghurt and other dairy products (Intestinal Microecology Group, 1977; Malhotra, 1977). In two population-based case-control studies of colon cancer, an inverse association was observed for yoghurt (Peters et al. 1992) and cultured milk (Young \& Wolf, 1988), adjusted for potential confounding factors. An inverse relationship has been demonstrated between the frequency of consumption of yoghurt and other fermented milk products and breast cancer in women (Le et al. 1986; van't Veer et al. 1989). On the other hand, two companion American prospective studies, the 1980-1988 follow-up of the Nurses' Health Study and the 19861990 Health Professionals follow-up study, did not provide evidence that intake of dairy products is associated with a decreased risk of colon cancer (Kampman et al. 1994a). In a cohort study in the Netherlands, it was shown that the intake of fermented dairy products was not significantly associated with colorectal cancer risk in an elderly population with a relatively wide variation in dairy product consumption, although a weak non-significant inverse association with colon cancer was observed (Kampman et al. 1994b).

\section{Mechanisms by which lactic acid bacteria may be inhibiting colon cancer}

There are several good animal models for colon cancer, which have proved useful for identifying dietary factors that may be protective. End points used are tumours themselves, or early lesions, such as aberrant crypt foci (ACF). ACF are putative preneoplastic lesions from which adenomas and carcinomas may develop. In recent years, there have been many studies using animal models, which have clearly demonstrated a protective effect of dietary supplements of LAB against colon tumour development (Hirayama \& Rafter, 2000; Lee \& Lee, 2000; Yamazaki et al. 2000).

The precise mechanisms by which LAB may inhibit colon cancer are presently unknown. However, mechanisms may include: alteration of the metabolic activities of intestinal microflora; alteration of physico-chemical conditions in the colon; binding and degrading potential carcinogens; quantitative and/or qualitative alterations in the intestinal microflora incriminated in producing putative carcinogen(s) and promoters (e.g. bile acid-metabolising bacteria); production of antitumourigenic or antimutagenic compounds; enhancing the host's immune response and effects on physiology of the host.

\section{Alteration of the metabolic activities of intestinal microflora}

Many foreign compounds are detoxified by glucuronide formation in the liver before entering the intestine via the bile. The bacterial enzyme $\beta$-glucuronidase has the ability to hydrolyse many glucuronides due to its wide substrate specificity, and thus may liberate carcinogenic aglycones in the intestinal lumen. Several other bacterial enzymes have also been suggested to be implicated in the carcinogenic process, releasing carcinogens in the intestinal tract. Interestingly, it was the observation that adding LAB supplements to the diets of rodents significantly decreased the activities of some of the faecal enzyme activities which focused attention on these bacteria as possible anticancer agents (Goldin \& Gorbach, 1984a; Kulkarni \& Reddy, 1994; Abdelali et al. 1995; Rowland et al. 1998). LAB have also reduced the specific activities of faecal enzymes in human volunteer studies (Ayebo et al. 1980; Goldin et al. 1980; Ling et al. 1994; Spanhaak et al. 1998). Goldin \& Gorbach (1984b) studied the effect of feeding Lactobacillus acidophilus strains NCFM and N-2 on the activity of three bacterial enzymes - $\beta$-glucuronidase, nitroreductase and azoreductase - in twenty-one healthy volunteers. Both strains had similar effects and caused a significant decline in the specific activity of the three enzymes in all subjects after 10 days of feeding. A reversal of the effect was observed within 10-30 days of ceasing Lactobacillus feeding, suggesting that continuous consumption of these bacteria was necessary to maintain the effect. The authors suggested that the observed reduction of these enzymes may explain the reduced colon cancer incidence that they saw in an earlier study in rats fed viable L. acidophilus (Goldin \& Gorbach, 1980). Thus in summary, animal and human studies indicate that feeding certain lactic cultures can result in a decrease of faecal enzymes that may be involved in formation of carcinogens. It is important to note that the studies to date do not always find reductions in the same enzymes, although findings with $\beta$-glucuronidase and nitroreductase are the most consistent. However, it is still unknown how or whether a reduction in these enzyme activities affects cancer rates in man. Indeed, the origin of the carcinogens causing colon cancer in man is still largely unknown.

\section{Alteration of physico-chemical conditions in the colon}

Modler et al. (1990) have suggested that large bowel cancer could be influenced directly by reducing intestinal $\mathrm{pH}$, thereby preventing the growth of putrefactive bacteria. In rats given inulin-containing diets with or without Bifidobacterium longum, an increase in caecal weight and $\beta$-glucosidase and a decrease in caecal $\mathrm{pH}$ were observed (Rowland et al. 1998), though some other studies did not detect a significant change in intestinal pH (Bartram et al. 1994; Abdelali et al. 1995).

Dietary fat has been considered a risk factor for colon cancer, and it has been suggested that its effect may be mediated by increased levels of bile acids (mainly secondary bile acids, produced by the action of bacterial $7 \alpha$-dehydroxylase on primary bile acids) in the colon (Weisburger \& Wynder, 1987). One hypothesis regarding colon carcinogenesis involves a cytotoxic effect on the colonic epithelium exerted by soluble bile acids in the aqueous phase, followed by an increased cell proliferation (Bruce, 1987). It has been demonstrated that a 6-week administration of L. acidophilus fermented milk supplements to colon 
cancer patients resulted in lower, though not significantly lower, concentrations of soluble bile acids in faeces (Lidbeck et al. 1991). In another study, patients with colonic adenomas participated in a 3-month study, where L. acidophilus was administered together with Bifodobacterium bifidum (Biasco et al. 1991). During this period, faecal $\mathrm{pH}$ was reduced significantly and patients having a higher proliferative activity in the upper colonic crypts than that calculated for subjects at low risk for colon cancer, showed a significant decrease after therapy with the LAB. In view of the results in the study by Lidbeck et al. (1991) it is interesting to speculate that the effect observed by Biasco et al. (1991) was in part due to decreased levels of bile acids in the aqueous phase.

\section{Binding and degrading potential carcinogens}

The bacterial cell wall in addition to the cell wall of certain plants may be an important factor in determining the ratio of bound to free (bioavailable) toxins in the intestine. Mutagenic compounds, commonly found in the Western meat-rich diet, can be bound to LAB in vitro. The extent of binding correlated well with the reduction in mutagenicity observed after exposure to the bacterial strains (Orrhage et al. 1994). Morotomi \& Mutai (1986) investigated the ability of twenty-two strains of intestinal bacteria to bind the mutagenic pyrolysates and compared their ability to that of some dietary fibres. 3-Amino-1,4dimethyl-5H-pyrido[4,3- $b$ ]indole (Trp-P-1) and 3-amino-1methyl-5H-pyrido[4,3- $b$ ]indole (Trp-P-2) were effectively bound to all Gram-positive and some Gram-negative bacterial cells, corn bran, apple pulp and soyabean fibre. When the mechanism of binding of Trp-P-2 to L. casei YIT 9018 and corn bran was investigated, it was shown to be $\mathrm{pH}$ dependent, instantaneous and was inhibited by the addition of metal salts, indicating a cation-exchange mechanism. The mutagenicity of Trp-P-2 for Salmonella typhimurium TA98 in the presence of S9 mix was inhibited by the addition of $L$. casei YIT 9018 to the reaction mixture, indicating that bound Trp-P-2 did not cause mutation under the assay conditions.

Although little is known about the fate of bound mutagens in the human gastrointestinal system, Zhang \& Ohta (1993) showed that freeze-dried cells of LAB, intestinal bacteria and yeast significantly reduced the absorption of Trp-P-1 from the small intestine in rats and that this was accompanied by decreased levels of this food mutagen in blood. In addition, consumption of lactobacilli by human volunteers has been shown to reduce the mutagenicity of urine and faeces associated with the ingestion of carcinogens in cooked meat (Lidbeck et al. 1992; Hayatsu \& Hayatsu, 1993). Administration of L. acidophilus to healthy volunteers consuming a fried meat diet, known to increase faecal mutagenicity, resulted in a greater decrease in faecal mutagenic activity after three days than administration of ordinary fermented milk (Lidbeck et al. 1992). During L. acidophilus administration, the urinary mutagenic activity on days 2 and 3 was significantly lower compared to the ordinary fermented milk period. In most cases, an increase in the number of faecal lactobacilli corresponded to a lower mutagen excretion, particularly in urine. Hayatsu \& Hayatsu (1993) also demonstrated a marked suppressing effect of orally administered Lactobacillus casei Shirota (LcS) on the urinary mutagenicity arising from ingestion of fried ground beef in man. In view of the in vitro results referred to earlier, it is possible that the LAB supplements are influencing excretion of mutagens by simply binding them in the intestine. Lactobacilli have also been shown to degrade nitrosamines (Rowland \& Grasso, 1975).

\section{Quantitative and/or qualitative alterations in the intestinal microflora}

Consumption of fermented milk containing L. acidophilus has been shown to significantly reduce the counts of faecal putrefactive bacteria such as coliforms and increase the levels of lactobacilli in the intestine (Ayebo et al. 1980; Shahani \& Ayebo, 1980) suggesting that supplemental L. acidophilus has a beneficial effect on the intestinal microecology by suppressing the putrefactive organisms that are possibly involved in the production of tumour promoters and putative precarcinogens. However, the mechanisms underlying these effects are still to a large extent not understood.

\section{Production of antitumourigenic or antimutagenic compounds}

There is evidence for antitumour activities of LAB obtained from studies using pre-implanted tumour cells in animal models. It has been demonstrated that feeding of fermented milk or cultures containing LAB inhibited the growth of tumour cells injected into mice (Kato et al. 1981; Friend et al. 1982). Repeated intralesional injection of live or dead Bifidobacterium cells inhibited the growth of Meth-A tumour cells transplanted subcutaneously into syngenic $B A L B / c$ mice (Kohwi et al. 1978). Sekine et al. (1994), using whole peptidoglycan isolated from Bifodbacterium infantis strain ATCC15697, reported that a single subcutaneous injection significantly suppressed tumour growth. In addition, five intralesional injections resulted in $70 \%$ tumour regression in the mice.

LAB or a soluble compound produced by the bacteria may interact directly with tumour cells in culture and inhibit their growth (Reddy et al. 1973, 1983). LAB significantly reduced the growth and viability of the human colon cancer cell line HT-29 in culture and dipeptidyl peptidase IV and brush border enzymes were significantly increased, suggesting that these cells may have entered a differentiation process (Baricault et al. 1995). Milk fermented by $B$. infantis, B. bifidum, Bifidobacterium animalis, Lactobacillus acidophilus and Lactobacillus paracasei inhibited the growth of the MCF7 breast cancer cell line and the anti-proliferative effect was not related to the presence of bacteria (Biffi et al. 1997). These findings suggest the presence of an ex novo soluble compound produced by LAB during milk fermentation or the microbial transformation of some milk components in a biologically active form. 


\section{Enhancing the host's immune response}

One explanation for tumour suppression by LAB may be mediated through an immune response of the host. Sekine et al. (1985) suggested that B. infantis stimulates the host-mediated response, leading to tumour suppression or regression. In addition, there are studies to suggest that LAB play an important role and function in the host's immunoprotective system by increasing specific and nonspecific mechanisms to have an antitumour effect (Kato et al. 1983; De Simone et al. 1993; Schiffrin et al. 1995). LcS has been shown to have potent antitumour and antimetastatic effects on transplantable tumour cells and to suppress chemically induced carcinogenesis in rodents. Also, intrapleural administration of $\mathrm{LcS}$ into tumour-bearing mice has been shown to induce the production of several cytokines, such as interferon- $\gamma$, interleukin- $1 \beta$ and tumour-necrosis factor- $\alpha$, in the thoracic cavity of mice, resulting in the inhibition of tumour growth and increased survival (Matsuzaki, 1998). These findings suggest that treatment with $\mathrm{LcS}$ has the potential to ameliorate or prevent tumourigenesis through modulation of the host's immune system, specifically cellular immune responses. An additional study has indicated that oral administration of BLP, a preparation of viable $L$. casei YIT 9018, potentiated systemic immune responses that modified T-cell functions in tumour-bearing mice (Kato et al. 1994). It has also been demonstrated that $B$. longum and B. animalis promote the induction of inflammatory cytokines (interleukin-6, tumour-necrosis factor$\alpha)$ in mouse peritoneal cells (Sekine et al. 1994).

\section{Effects on the physiology of the host}

Lactobacilli are one of the dominant species in the small intestine, and these micro-organisms presumably affect metabolic reactions occurring in this part of the gastrointestinal tract. The ileal mucosa (Venitt, 1988) as well as the colonic mucosa (Fang \& Strobel, 1978) have the capacity to absorb mutagenic compounds from the intestinal lumen whereafter the compounds are passed into the bloodstream, either unchanged or as metabolites. In addition, $\mathrm{LAB}$ have been shown to increase colonic NADPH-cytochrome P-450 reductase activity (Pool-Zobel et al. 1996) and glutathione S-transferase levels (Challa et al. 1997) and to reduce hepatic uridine diphosphoglucuronyl transferase activity (Abdelali et al. 1995), enzymes which are involved in the metabolism of carcinogens in rats. Arimochi et al. (1997) showed an inhibitory effect of L. acidophilus on ACF formation in the colon of rats, induced by azoxymethane, and enhanced removal of $\mathrm{O}^{6}$ methylguanine from the colon mucosal DNA and that these effects came from culture supernatants, not from bacterial cells. ACF are putative preneoplastic lesions from which adenomas and carcinomas may develop. In addition, it has been demonstrated that dietary administration of lyophilized cultures of B. longum strongly suppressed azoxymethane-induced colonic tumour development and that this effect was associated with a decrease in colonic mucosal cell proliferation and colonic mucosal and tumour ornithine decarboxylase and ras-p21 activities (Reddy, 1998).

\section{Conclusion}

There are several possible mechanisms that may explain how LAB may protect against tumour development in the colon. However, questions such as: what is the major contributing mechanism for a particular bacterial strain or how are the different mechanisms linked are questions to which we presently do not have the answers. It is possible that different strains target different mechanisms. All of the mechanisms have various degrees of support, mainly derived from in vitro and animal experiments. Some of them also have some support from human clinical studies. More work needs to be done to identify the specific strains and strain characteristics responsible for specific antitumour effects and the mechanisms by which these effects are mediated. However, even with the limited information available, the use of lactic cultures for human cancer suppression holds promise and certainly deserves more scrutiny. Carefully designed human clinical trials are needed to corroborate the wealth of experimental studies. Such a clinical trial is presently ongoing (SYNCAN, 2001), i.e. to examine the effect of a synbiotic preparation on colon cancer risk biomarkers in man (SYNCAN project, funded by EU, and involving eight research centres in Europe). It involves a 12-week randomised, double-blind, placebocontrolled trial of a food supplement containing Lactobacillus GG, Bifidobacterium Bb-12 and Raftilose Synergyl in adenoma patients. In this study, all of the 'state-of-theart' colon cancer risk biomarkers, including colonic mucosal markers, faecal water markers and immunological markers, are being measured. In parallel, a long-term tumourigenesis study in rats, using the same synbiotic combination and assaying for the same biomarkers, is being carried out. It is hoped that the results of this study will provide much needed information on the cancer protective effects of synbiotics in man and supply us with additional valuable information on underlying mechanisms.

\section{References}

Abdelali H, Cassand P, Soussotte V, Daubeze M, Bouley C \& Narbonne JF (1995) Effect of dairy products on initiation of precursor lesions of colon cancer in rats. Nutrition and Cancer 24, 121-132.

Arimochi H, Kinouchi T, Kataoka K, Kuwahara T \& Ohnishi Y (1997) Effect of intestinal bacteria on formation of azoxymethane-induced aberrant crypt foci in the rat colon. Biochemical and Biophysical Research Communications 238, 753-757.

Ayebo AD, Angelo IA \& Shahani KM (1980) Effect of ingesting Lactobacillus acidophilus milk upon fecal flora and enzyme activity in humans. Milchwissenschaft 35, 730-733.

Baricault L, Denariaz G, Houri J-J, Bouley C, Sapin C \& Trugnan G (1995) Use of HT-29, a cultured human colon cancer cell line, to study the effect of fermented milks on colon cancer cell growth and differentiation. Carcinogenesis 16, 245-252.

Bartram HP, Scheppach W, Gerlach S, Ruckdeschel G, Kelber E \& Kasper H (1994) Does yogurt enriched with Bifidobacterium 
longum affect colonic microbiology and fecal metabolites in healthy subjects? American Journal of Clinical Nutrition 59, 428-432.

Biasco G, Paganelli G, Brandi G, Brillianti S \& Lami F (1991) Effect of Lactobacillus acidophilus and Bifidobacterium bifidum on rectal cell kinetics and fecal $\mathrm{pH}$. Italian Journal of Gastroenterology 23, 142.

Biffi A, Coradini D, Larsen R, Riva L \& Di Fronzo G (1997) Antiproliferative effect of fermented milk on the growth of a human breast cancer cell line. Nutrition and Cancer 28, 93-99.

Bruce WR (1987) Recent hypotheses for the origin of colon cancer. Cancer Research 47, 4237-4242.

Challa A, Rao DR, Chawan CB \& Shackelford L (1997) Bifidobacterium longum and lactulose suppress azoxymethaneinduced colonic aberrant crypt foci in rats. Carcinogenesis 18, 517-521.

De Simone C, Vesely R, Bianchi Salvadori B \& Jirillo E (1993) The role of probiotics in modulation of the immune system in man and in animals. International Journal of Immunotherapy 9, 23-28.

Fang W-F \& Strobel HW (1978) Activation of carcinogens and mutagens by rat colon mucosa. Cancer Research 38, 29392944.

Friend BA, Farmer RE \& Shahani KM (1982) Effect of feeding and intraperitoneal implantation of yogurt culture cells on Ehrlich ascites tumour. Milchwissenschaft 37, 708-710.

Goldin BR \& Gorbach SL (1980) Effect of Lactobacillus acidophilus dietary supplements on 1,2-dimethylhydrazine dihydrochloride-induced intestinal cancer in rats. Journal of the National Cancer Institute 64, 263-265.

Goldin BR \& Gorbach SL (1984a) Alterations of the intestinal microflora by diet, oral antibiotics and Lactobacillus: decreased production of free amines from aromatic nitro compounds, azo dyes and glucuronides. Journal of the National Cancer Institute 73, 689-695.

Goldin BR \& Gorbach SL (1984b) The effect of milk and lactobacillus feeding on human intestinal bacterial enzyme activity. American Journal of Clinical Nutrition 39, 756-761.

Goldin BR, Swenson L, Dwyer J, Sexton M \& Gorbach SL (1980) Effect of diet and Lactobacillus acidophilus supplements on human fecal bacterial enzymes. Journal of the National Cancer Institute 64, 255-261.

Hayatsu H \& Hayatsu T (1993) Suppressing effect of Lactobacillus casei administration on the urinary mutagenicity arising from ingestion of fried ground beef in the human. Cancer Letters 73, 173-179.

Hirayama K \& Rafter J (2000) The role of probiotic bacteria in cancer prevention. Microbes and Infection 2, 681-686.

Intestinal Microecology Group, International Agency for Research on Cancer (1977) Dietary fibre, transit time, fecal bacteria, steroids and colon cancer in two Scandinavian populations. Lancet 2, 207-211.

Kampman E, Giovannucci E, van't Veer P, Rimm E, Stampfer MJ, Colditz GA, Kok FJ \& Willett WC (1994a) Calcium, vitamin D, dairy foods and the occurrence of colorectal adenomas among men and women in two prospective studies. American Journal of Epidemiology 139, 16-29.

Kampman E, Goldbohm RA, van den Brandt PA \& van't Veer P (1994b) Fermented dairy products, calcium and colorectal cancer in the Netherlands cohort study. Cancer Research 54, 3186-3190.

Kato I, Endo K \& Yokokura T (1994) Effects of oral administration of Lactobacillus casei on antitumour responses induced by tumour resection in mice. International Journal of Immunopharmacology 16, 29-36.

Kato I, Kobayashi S, Yokokura T \& Mutai M (1981) Antitumour activity of Lactobacillus casei in mice. Gann 72, 517-523.

Kato I, Yokokura T \& Mutai M (1983) Macrophage activation by
Lactobacillus casei in mice. Microbiology and Immunology 27, 611-618.

Kohwi T, Imai K, Tamura A \& Hashimoto Y (1978) Antitumour effect of Bifidobacterium infantis in mice. Gann 69, 613-618.

Kulkarni N \& Reddy BS (1994) Inhibitory effect of Bifidobacterium longum cultures on the azoxymethane-induced aberrant crypt foci formation and fecal bacterial $\beta$-glucuronidase. Proceedings of the Society for Experimental Biology and Medicine 207, 278-283.

Le MG, Moulton LH, Hill C \& Kramer A (1986) Consumption of dairy produce and alcohol in a case-control study of breast cancer. Journal of the National Cancer Institute 77, 633-636.

Lee S-M \& Lee W-K (2000) Inhibitory effects of lactic acid bacteria (LAB) on the azoxymethane-induced colonic preneoplastic lesions. Journal of Microbiology 38, 169-175.

Lidbeck A, Geltner-Allinger U, Orrhage KM, Ottava L, Brismar B, Gustafsson J-A, Rafter JJ \& Nord CE (1991) Impact of Lactobacillus acidophilus supplements on the faecal microflora and soluble faecal bile acids in colon cancer patients. Microbial Ecology in Health \& Disease 4, 81-88.

Lidbeck A, Overvik E, Rafter J, Nord CE \& Gustafsson J-A (1992) Effect of Lactobacillus acidophilus supplements on mutagen excretion in feces and urine in humans. Microbial Ecology in Health \& Disease 5, 59-67.

Ling WH, Korpela R, Mykkanen H, Salminen S \& Hanninen O (1994) Lactobacillus strain GG supplementation decreases colonic hydrolytic and reductive enzyme activities in healthy female adults. Journal of Nutrition 124, 18-23.

Malhotra SL (1977) Dietary factors in a study of colon cancer from cancer registry, with special reference to the role of saliva, milk and fermented milk products and vegetable fibre. Medical Hypotheses 3, 122-134.

Matsuzaki T (1998) Immunomodulation by treatment with Lactobacillus casei strain Shirota. International Journal of Food Microbiology 41, 133-140.

Modler GW, McKellar RC \& Yaguchi M (1990) Bifidobacteria and bifidogenic factors. Canadian Institute of Food Science and Technology Journal 23, 29-41.

Morotomi M \& Mutai M (1986) In vitro binding of potent mutagenic pyrolysates to intestinal bacteria. Journal of the National Cancer Institute 77, 195-201.

Orrhage K, Sillerstrom E, Gustafsson J-A, Nord CE \& Rafter J (1994) Binding of mutagenic heterocyclic amines by intestinal and LAB. Mutation Research 311, 239-248.

Peters RK, Pike MC, Garabrant D \& Mack TM (1992) Diet and colon cancer in Los Angeles County, California. Cancer Causes Control 3, 457-473.

Pool-Zobel BL, Neudecker C, Domizlaff I, Ji S, Schillinger U, Rumney C, Moretti M, Vilarini I, Scassellati-Sforzolini R \& Rowland I (1996) Lactobacillus- and Bifidobacterium-mediated antigenotoxicity in the colon of rats. Nutrition and Cancer 26, 365-380.

Reddy BS (1998) Prevention of colon cancer by pre- and probiotics: evidence from laboratory studies. British Journal of Nutrition 80, S219-S223.

Reddy GV, Friend BA, Shahani KM \& Farmer RE (1983) Antitumour activity of yogurt components. Journal of Food Protection 46, 8-11.

Reddy GV, Shahani KM \& Banerjee MR (1973) Inhibitory effect of yogurt on Ehrlich ascites tumour cell proliferation. Journal of the National Cancer Institute 50, 815-817.

Rowland IR \& Grasso P (1975) Degradation of $N$-nitrosamines by intestinal bacteria. Applied Microbiology 29, 7-12.

Rowland IR, Rumney CJ, Coutts JT \& Lievense LC (1998) Effect of Bifidobacterium longum and inulin on gut bacterial metabolism and carcinogen-induced aberrant crypt foci in rats. Carcinogenesis 19, 281-285. 
Salminen S, Bouley C, Boutron-Ruault M-C, Cummings JH, Franck A, Gibson GR, Isolauri E, Moreau M-C, Roberfroid M \& Rowland I (1998) Functional food science and gastrointestinal physiology and function. British Journal of Nutrition 80, Suppl. 1, S147-S171.

Sant M, Capocaccia E, Verdecchia A, Gatta G, Micheli A, Mariotto A, Hakulinen T \& Berrino F (1995) Comparisions of colon-cancer survival among European countries: The Eurocare Study. International Journal of Cancer 63, 43-48.

Schiffrin EJ, Rochat F, Link-Amster H, Aeschlimann JM \& Donnet-Hughes A (1995) Immunomodulation of human blood cells following the ingestion of LAB. Journal of Dairy Science 78, 491-496.

Sekine K, Kawashima T \& Hashimoto Y (1994) Comparison of the TNF- $\alpha$ levels induced by human-derived Bifidobacterium longum and rat-derived Bifidobacterium animalis in mouse peritoneal cells. Bifidobacteria Microflora 13, 79-89.

Sekine K, Toida T, Saito M, Kuboyama M, Kawashima T \& Hashimoto Y (1985) A new morphologically characterized cell wall preparation (whole peptidoglycan) from Bifidobacterium infantis with a higher efficacy on the regression of an established tumour in mice. Cancer Research 45, 1300-1307.

Shahani KM \& Ayebo AD (1980) Role of dietary lactobacilli in gastrointestinal microecology. American Journal of Clinical Nutrition 33, 2448-2457.

Spanhaak S, Havenaar R \& Schaafsma G (1998) The effect of consumption of milk fermented by Lactobacillus casei strain
Shirota on the intestinal microflora and immune parmeters in humans. European Journal of Clinical Nutrition 52, 899-907. SYNCAN (2001) www.snycan.be

van't Veer P, Dekker JM, Lamers JWJ, Kok FJ, Schouten EG, Brants HAM, Sturmans F \& Hermus RJJ (1989) Consumption of fermented milk products and breast cancer: a case-control study in the Netherlands. Cancer Research 49, 4020-4023.

Venitt S (1988) Mutagens in human faeces and cancer of the large bowel. In Role of the Gut Flora in Toxicity and Cancer, pp. 399-460 [I Rowland, editor]. London: Academic Press.

Weisburger JH \& Wynder EL (1987) Etiology of colorectal cancer with emphasis on mechanism of action and prevention. In Important Advances in Oncology, pp. 197-220 [VT De Vita, S Hellman and SA Rosenberg, editors]. Philadelphia: JB Lippincott.

Yamazaki K, Tsunoda A, Sibusawa M, Tsunoda Y, Kusano M, Fukuchi K, Yamanaka M, Kushima M, Nomoto K \& Morotomi M (2000) The effects of an oral administration of Lactobacillus casei Shirota on azoxymethane-induced colonic aberrant crypt foci and colon cancer in rats. Oncology Reports 7, 977-982.

Young TB \& Wolf DA (1988) Case-control study of proximal and distal colon cancer and diet in Wisconsin. International Journal of Cancer 42, 167-175.

Zhang XB \& Ohta Y (1993) Microorganisms in the gastrointestinal tract of the rat prevent absorption of the mutagen-carcinogen 3-amino-1,4-dimethyl-5H-pyrido[4,3-b ]indole. Canadian Journal of Microbiology 39, 841-845. 